\title{
Ageism and psychosocial variables during the COVID-19 pandemic: a scoping review protocol
}

\section{Idadismo e variáveis psicossociais durante a pandemia de COVID-19: um protocolo de scoping review}

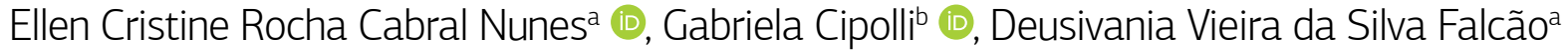

\begin{abstract}
OBJECTIVE: To map studies that focused on the effects of the coronavirus disease 2019 (COVID-19) pandemic on the mental health, well-being, self-perception of aging, and intergenerational relationships of older adults, and how ageism affected these psychosocial variables in this population during the pandemic. METHODS: We will use the Joanna Brings Institute (JBI) methodology and search for indexed literature published in English, Portuguese, and Spanish in 12 databases. Two authors will independently screen titles, abstracts, and full texts according to the following eligibility criteria: studies that focused on samples of older adults (minimum age 60 years old), considering community-dwelling older adults, and studies using (quantitative designs, whether cross-sectional or longitudinal). In addition, at least one variable and its relationship with the COVID-19 pandemic must be presented in the study. RESULTS: The results will be presented in a tabular format with a narrative summary.
\end{abstract}

KEYWORDS: ageism; mental health; well-being; self-concept; COVID-19; intergenerational relations.

OBJETIVO: Mapear estudos focados nos efeitos da pandemia de COVID-19 na saúde mental, bem-estar, autopercepção do envelhecimento e relações intergeracionais de pessoas idosas, além de como o idadismo afetou essas variáveis psicossociais em pessoas idosas durante a pandemia. METODOLOGIA: Utilizar-se-á metodologia do Instituto Joanna Briggs. A literatura indexada em inglês, espanhol e português será pesquisada em 12 bases de dados. Dois autores avaliarão os títulos, resumos e posteriormente o texto completo, após sua inclusão segundo os critérios estabelecidos, a saber: estudos focados em pessoas com no mínimo 60 anos; estudos com idosos residentes na comunidade; com delineamentos de pesquisa quantitativos (quantitativos, fossem eles transversais ou longitudinais); e que relacionem pelo menos uma variável com a pandemia de COVID-

19. RESULTADOS: Os resultados serão apresentados em formato tabular, com resumo narrativo.

PALAVRAS-CHAVE: idadismo; saúde mental; bem-estar; autopercepção; COVID-19; relações intergeracionais.

a'Graduate Program in Gerontology, School of Arts, Sciences, and Humanities, Universidade de São Paulo - São Paulo (SP), Brazil.

${ }^{\mathrm{b}} \mathrm{Graduate}$ Program in Gerontology, Universidade Estadual de Campinas - Campinas (SP), Brazil.

Correspondence data

Deusivania Vieira da Silva Falcão - Rua Arlindo Béttio, 1000 - Vila Guaraciaba - CEP: 03828-000 - São Paulo (SP), Brazil. E-mail: deusivania@usp.br. @deusivaniav Received on: 06/05/2021. Accepted on: 09/03/2021.

How to cite this article: Nunes ECRC, Cipolli GC, Falcão DVS. Ageism and psychosocial variables during the COVID-19 pandemic: a scoping review protocol. Geriatr Gerontol Aging. 2021;15:e0210041. https://doi.org/10.53886/gga.e0210041

https://doi.org/10.53886/gga.e0210041 


\section{INTRODUCTION}

In January 2020, the World Health Organization (WHO) declared the outbreak of the new coronavirus (SARS-CoV-2). The coronavirus disease 2019 (COVID-19) is a contagious disease that can cause, among other symptoms, fever and dry cough, and severe pneumonia in its most dangerous state. ${ }^{1}$ In this new social context, older adults were seen as the most affected age group with higher mortality rates. ${ }^{2}$ This social behavior led to an increase in prejudice against older adults, as well as in their isolation and social ostracism. ${ }^{3}$

The pandemic increased the intergenerational tension between the younger and older generations. ${ }^{4}$ There were more than 18128 tweets with the hashtag "Boomer Remover" in March 2020, a quarter of which had ageist content. Therefore, it is possible to infer that the pandemic increased the prejudice against older adults. ${ }^{3}$

The concept of ageism, or age prejudice, was established by Robert Butler in 1969. Ageism has three dimensions: the prejudice, or how a person feels about aging and older adults; stereotype, or the way we think about someone's age; and discrimination or actions towards age. ${ }^{5}$ Ageism can be found in all levels of life including the individual level, in relationships and social relations, institutions, and culture. Nevertheless, in this protocol, ageism will always be regarded as prejudice against older adults (aged 60 years and older). ${ }^{6}$

The experience of ageism has negative results on the mental health and well-being of older people, affecting their social relationships and increasing their chances of depression, anxiety, and negative overall health. ${ }^{7-13}$ It can also be linked to a negative self-perception of aging, according to studies that showed that poor self-perception of aging can also affect longevity and health. ${ }^{14,15}$

The pandemic has brought new challenges to the lives of older people, as previously shown. The $\mathrm{WHO}^{16}$ found that $93 \%$ of mental health services worldwide were disrupted. However, the demand for mental health increased. A scoping review is appropriate considering the expansion of the COVID-19 topic in the context of old age. Considering the aforementioned context, this scoping review protocol will map studies on the relationships of ageism, self-perception of aging, intergenerational relationships, mental health, and well-being in the context of the COVID-19 pandemic. The main objective is to provide a better understanding of how the pandemic jeopardized these aspects of older people's lives.

\section{RATIONALE}

The scope review intends to summarize and identify gaps in the existing literature. ${ }^{17}$ This scoping review will aim to supply an overview of the scientific literature produced until
July 2021 on the effects of the COVID-19 pandemic on the mental health, self-perception of aging, and well-being of older persons and their intergenerational relationships. Considering the social changes and the so-called "new normal," how was the older generation affected by these changes? It is important to add that the COVID-19 pandemic is still ongoing, as new variants are surging. ${ }^{18}$ The scoping review format was selected considering the unpredictable character of the situation and the primary nature of the research performed during this time.

Preliminary research was conducted in June 2021 on the PubMed database using the search strategy indicated below. We have not identified other identical proposals.

\section{METHODS}

The proposed scoping review will be performed using the frameworkestablished by Arksey and O'Malley in 2005. ${ }^{17}$ This framework was expanded by Levac, Colquhoun, and O'Brien, ${ }^{19}$ thus both methods are used as part of the Joanna Briggs Institute scoping review methodology. ${ }^{20}$ The Preferred Reporting Items for Systematic Reviews and Meta-Analyses extension for Scoping Reviews (PRISMA$\mathrm{ScR})^{21}$ checklist will be followed. This protocol is preregistered in the Open Science Framework (https://osf.io/kmf6).

\section{Ethical approval}

Since this protocol aims to present methodological information for the preparation of a scoping review, this study does not require ethical approval.

\section{Identifying the research question}

The research question that will guide this ewview is: "what are the effects of the COVID-19 pandemic on the mental health, self-perception of aging, well-being, and intergenerational relationships of community-dwelling older people?" This question will allow us to adequately capture the relevance of the existing literature in a comprehensive manner while providing the opportunity to add to or change the main research question as needed throughout the study. During the preliminary exploratory review, we identified only one minor question to guide the subsequent stages of the scoping review and to complement the main question above. This question will be included, but not limited to:

- What are the effects of ageism during the COVID19 pandemic on the mental health, self-perception of aging, well-being, and intergenerational relationships of community-dwelling older adults?

The population, concept, and context (PCC) framework recommended by the Joanna Briggs Institute ${ }^{22}$ for scoping 
reviews will be used in this protocol to determine the research question and eligibility criteria. Studies will be selected according to the inclusion and exclusion criteria.

The following studies will be considered:

- Studies with community-dwelling older adults (60 years old and older), men and/or women (average age at least 60) [participants];

- Gerontological literature that explores the relationship between ageism and self-perception of aging; ageism and its effects on the intergenerational relationships, mental health, and well-being of older adults; the relationships between ageism, its effects on mental health, well-being, and self-perception of aging [concept];

- Studies published in the context of the COVID-19 pandemic that explore its results in the lives of older adults and its relationship with the selected variables [context];

- Studies using cross-sectional or longitudinal designs;

- Studies that discuss at least one variable and its relationship with the COVID-19 pandemic;

- Studies fully published in English, Portuguese, and Spanish.

Articles will be excluded if they are:

- Not fully published in the languages described above;

- Gray literature (ie, books, theses, dissertations);

- Case reports, letters to the editor, qualitative studies, case-control studies, cohort studies, experimental studies, comments, or opinion pieces;

- Studies that compare the reaction of the younger generation (children and young adults) to older adults;

- Reporting older adults who had symptoms and/or who were hospitalized for COVID-19;

- Focused only on a sample of older adults with a specific disease (ie, psychiatric or chronic diseases such as diabetes or dementia);

- Exclusively theoretical.

\section{Identifying relevant studies}

The databases selected for this review are PubMed, Scopus, Ageline, PsycINFO,Web of Science,LILACS, BVS-BIREME, EMBASE, CINAHL, COCHRANE(OVID), PROQUEST, and MEDLINE. Research will be performed using the following search strategy: (aged OR "aged, 80 and over" OR "old people" OR "old adults" OR seniors) AND (ageism OR stereotyping OR "self concept" OR "mental health" OR wellbeing OR "well-being" OR “intergenerational relations") AND aging AND ((“coronavirus infections" OR “COVID-19”) AND pandemics). The search strategy using these keywords was developed with the collaboration of a specialized librarian and will be performed in all the selected databases. The period established for the search will be from 2019 to July 2021.

The search strategy will follow 3 steps: first, an initial search will be conducted on PubMed, followed by the analysis of titles and abstracts. A second search will be performed using the full strategy and the Medical Subject Headings (MeSH) terms identified on all the databases selected by the authors. Finally, the reference lists will be tracked for possible additional studies. Only articles published from the year 2020 forward will be considered (Table 1 ).

\section{Selecting studies}

Two authors will select the studies using the inclusion criteria and Rayyan (https://rayyan.qcri.org/welcome), a website and mobile app for systematic reviews. Both authors will analyze the titles and abstracts of the selected articles. In case of disagreement, a third author will be consulted. Afterwards, the selected articles will be fully read by the two authors, and in case of divergences, these will be solved through consensus. The dates of selected studies will be imported to the Endnote Web Library, where they will be reviewed, and the reference lists of the selected studies will be checked. The review will have inclusion and exclusion criteria in accordance with the PCC structure recommended for scope reviews.

\section{Charting data}

Relevant data for this review will be extracted from the included studies by two independent reviewers using methods recommended by Peters et al. ${ }^{20}$ Furthermore, data extraction will include author(s), date, title, journal, volume, issue, pages, country, type of study, objectives, sample size, population characteristics (age and gender), context, methods, instruments (mental health, intergenerational relationship, self-perception, ageism, and well-being), and results. The scope review will verify how the COVID-19 pandemic affected the lives of older adults, using the variables established above as parameter. Therefore, data extraction will be done using the research question as the focus.

\section{Presenting results}

The decision process for this review will be presented in a flowchart, including the research results, removal of duplicate citations, study selection phases (title/abstract and full text), reasons for excluding articles after screening the full text, and final number of included studies. In order to illustrate this process, a PRISMA flow diagram will be used. Participant data, concept, and context (PCC) will be presented and may also be displayed through graphs, maps, or other tables to properly map the results and highlight the level and amount of evidence in the studies. A data presentation table will be constructed from the extracted data, being grouped according to the gaps observed in the research. 
Table 1. Checklist of the Preferred Reporting Items for Systematic reviews and Meta-Analyses (PRISMA-ScR) extension for Scoping Reviews. ${ }^{21}$

\begin{tabular}{|c|c|c|}
\hline Section & Item & PRISMA-ScR checklist item \\
\hline Title & 1 & Identify the report as a scoping review. \\
\hline Structured summary & 2 & $\begin{array}{l}\text { Provide a structured summary that includes (as applicable): background, objectives, } \\
\text { eligibility criteria, sources of evidence, charting methods, results, and conclusions that } \\
\text { relate to the review questions and objectives. }\end{array}$ \\
\hline Rationale & 3 & $\begin{array}{l}\text { Describe the rationale for the review in the context of what is already known. Explain why } \\
\text { the review questions/objectives lend themselves to a scoping review approach. }\end{array}$ \\
\hline Objectives & 4 & $\begin{array}{l}\text { Provide an explicit statement of the questions and objectives being addressed with } \\
\text { reference to their key elements (eg, population or participants, concepts, and context) or } \\
\text { other relevant key elements used to conceptualize the review questions and/or objectives. }\end{array}$ \\
\hline Protocol and registration & 5 & $\begin{array}{l}\text { Indicate whether a review protocol exists; state if and where it can be accessed } \\
\text { (eg, a Web address); and if available, provide registration information, including the } \\
\text { registration number. }\end{array}$ \\
\hline Eligibility criteria & 6 & $\begin{array}{l}\text { Specify characteristics of the sources of evidence used as eligibility criteria (eg, years } \\
\text { considered, language, and publication status), and provide a rationale. }\end{array}$ \\
\hline Information sources* & 7 & $\begin{array}{l}\text { Describe all information sources in the search (eg, databases with dates of coverage and } \\
\text { contact with authors to identify additional sources), as well as the date the most recent } \\
\text { search was executed. }\end{array}$ \\
\hline Search & 8 & $\begin{array}{l}\text { Present the full electronic search strategy for at least } 1 \text { database, including any limits used, } \\
\text { such that it could be repeated. }\end{array}$ \\
\hline $\begin{array}{l}\text { Selection of sources of } \\
\text { evidencet }\end{array}$ & 9 & $\begin{array}{l}\text { State the process for selecting sources of evidence (ie, screening and eligibility) included in } \\
\text { the scoping review. }\end{array}$ \\
\hline Data charting process $\neq$ & 10 & $\begin{array}{l}\text { Describe the methods of charting data from the included sources of evidence (eg, } \\
\text { calibrated forms or forms that have been tested by the team before their use, and whether } \\
\text { data charting was done independently or in duplicate) and any processes for obtaining and } \\
\text { confirming data from investigators. }\end{array}$ \\
\hline Data items & 11 & $\begin{array}{l}\text { List and define all variables for which data were sought and any assumptions and } \\
\text { simplifications made. }\end{array}$ \\
\hline $\begin{array}{l}\text { Critical appraisal of } \\
\text { individual sources of } \\
\text { evidence§ }\end{array}$ & 12 & $\begin{array}{l}\text { If done, provide a rationale for conducting a critical appraisal of included sources of } \\
\text { evidence; describe the methods used and how this information was used in any data } \\
\text { synthesis (if appropriate). }\end{array}$ \\
\hline Synthesis of results & 13 & Describe the methods of handling and summarizing the data that were charted. \\
\hline $\begin{array}{l}\text { Selection of sources of } \\
\text { evidence }\end{array}$ & 14 & $\begin{array}{l}\text { Give numbers of sources of evidence screened, assessed for eligibility, and included in the } \\
\text { review, with reasons for exclusions at each stage, ideally using a flow diagram. }\end{array}$ \\
\hline $\begin{array}{l}\text { Characteristics of sources } \\
\text { of evidence }\end{array}$ & 15 & $\begin{array}{l}\text { For each source of evidence, present characteristics for which data were charted and } \\
\text { provide the citations. }\end{array}$ \\
\hline $\begin{array}{l}\text { Critical appraisal within } \\
\text { sources of evidence }\end{array}$ & 16 & If done, present data on critical appraisal of included sources of evidence (see item 12). \\
\hline $\begin{array}{l}\text { Results of individual } \\
\text { sources of evidence }\end{array}$ & 17 & $\begin{array}{l}\text { For each included source of evidence, present the relevant data that were charted that } \\
\text { relate to the review questions and objectives. }\end{array}$ \\
\hline Synthesis of results & 18 & $\begin{array}{l}\text { Summarize and/or present the charting results as they relate to the } \\
\text { review questions and objectives. }\end{array}$ \\
\hline Summary of evidence & 19 & $\begin{array}{l}\text { Summarize the main results (including an overview of concepts, themes, and types of } \\
\text { evidence available), link to the review questions and objectives, and consider the relevance } \\
\text { to key groups. }\end{array}$ \\
\hline Limitations & 20 & Discuss the limitations of the scoping review process. \\
\hline Conclusions & 21 & $\begin{array}{l}\text { Provide a general interpretation of the results with respect to the review questions and } \\
\text { objectives, as well as potential implications and/or next steps. }\end{array}$ \\
\hline Funding & 22 & $\begin{array}{l}\text { Describe sources of funding for the included sources of evidence, as well as sources of } \\
\text { funding for the scoping review. Describe the role of the funders of the scoping review. }\end{array}$ \\
\hline
\end{tabular}




\section{Relevance and dissemination}

This study may help clarify the understanding of the effects of the COVID-19 pandemic on the health, well-being, relationships, and self-perception of aging of older adults. Moreover, it will map the research on these variables and the social alterations caused by the pandemic context. Results from this review may assist in the development of mental health programs focused on older adults. Furthermore, they will illustrate the results of isolation and exclusion during the social distancing period and the relevance of raising awareness about the existence of ageism worldwide and its increase during the COVID-19 pandemic. The complete scoping review will be disseminated through publication in an international peer-reviewed journal, social media platforms, and presentations at conferences on aging.

\section{ACKNOWLEDGMENTS}

The authors gratefully acknowledge the contribution of Ana Paula Morais e Oliveira, who is a librarian at Universidade
Estadual de Campinas (Brazil), and her specialized support during the search process.

\section{CONFLICTS OF INTEREST}

The authors declare no conflicts of interest.

\section{FUNDING}

This study was financed in part by the Coordenação de Aperfeiçoamento de Pessoal de Nível Superior - Brasil (CAPES) - Finance Code 001.

\section{AUTHORS' CONTRIBUTION}

ECRCN: conceptualization, writing - review \& editing. DVSF: conceptualization, writing - review \& editing. GCC: conceptualization, writing — review \& editing.

\section{REFERENCES}

1. Organização Pan-Americana da Saúde. Folha informativa sobre COVID-19. Available from: https://uww.paho.org/pt/covid19. Accessed in Jun 4, 2021.

2. Ayalon $L$. There is nothing new under the sun: ageism and intergenerational tension in the age of the COVID-19 outbreak. Int Psychogeriatr. 2020;32(10):1221-4. https://doi.org/10.1017/ S1041610220000575

3. Previtali F, Allen LD, Varlamova M. Not only virus spread: the diffusion of ageism during the outbreak of COVID-19.) Aging Soc Policy. 2020;32(45):506-14. https://doi.org/10.1080/08959420.2020.1772002

4. Jimenez-Sotomayor MR, Gomez-Moreno C, Soto-Perez-de-Celis E. Coronavirus, ageism, and twitter: an evaluation of tweets about older adults and COVID-19. J Am Geriatr Soc. 2020;68(8):1661-5. https://doi.org/10.1111/jgs.16508

5. Marques S, Mariano J, Mendonça J, De Tavernier W, Hess M, Naegele $L$, et al. Determinants of Ageism against Older Adults: A Systematic Review. Int J Environ Res Public Health. 2020; 17(7):2560. https:// doi.org/10.3390/ijerph17072560

6. Iversen TN, Larsen L, Solem, PE. A conceptual analysis of ageism. Nordic Psychology. 2009;61(3):4-22. https://doi.org/10.1027/1901-2276.61.3.4

7. World Health Organization. Global report on Ageism. Available from: https:// unw.who.int/publications/i/item/9789240016866. Accessed in Jun 4,2021.

8. Levy BR, Hausdorff JM, Hencke R, Wei JY. Reducing Cardiovascular Stress With Positive Self-Stereotypes of Aging. Journals Gerontol Ser B. 2000;55(4):P205-13. https://doi.org/10.1093/geronb/55.4.P205

9. Voss P, Bodner E, Rothermund K. Ageism: the relationship between age stereotypes and age discrimination. In: Ayalon L, Tesch-Römer C, eds. Contemporary perspectives on ageism. international perspectives on aging. Cham: Springer; 2008. p. 11-31.

10. Levy BR, Slade MD, Murphy TE, Gill TM. Association between positive age stereotypes and recovery from disability in older persons. JAMA. 2012;308(19):1972-3. https://doi.org/10.1001/jama.2012.14541

11. Kim H, Thyer BA, Munn JC. The relationship between perceived ageism and depressive symptoms in later life: understanding the mediating effects of self-perception of aging and purpose in life, using structural equation modeling. Educ Gerontol. 2019;45(2):10519. https://doi.org/10.1080/03601277.2019.1583403
12. Allen JO. Ageism as a risk factor for chronic disease. Gerontologist. 2016;56(4):610-4. https://doi.org/10.1093/geront/gnu158

13. Gu D, Dupre ME, Qiu L. Self-perception of uselessness and mortality among older adults in China. Arch Gerontol Geriatr. 2017;1 (68):18694. https://doi.org/10.1016/j.archger.2016.10.015

14. Moser C, Spagnoli J, Santos-Eggimann B. Self-perception of aging and vulnerability to adverse outcomes at the age of 65-70 years. J Gerontol B Psychol Sci Soc Sci. 2011;66B(6):675-80. https://doi. org/10.1093/geronb/gbr052

15. Luo MS, Li LW, Hu RX. Self-perceptions of aging and domain-specific health outcomes among midlife and later-life couples. J Aging Health 2021;33(1-2):155-66. https://doi.org/10.1177/0898264320966263

16. World Health Organization. COVID-19 disrupting mental health services in most countries, WHO survey. Available from: https://www.who.int/ news/item/05-10-2020-covid-19-disrupting-mental-health-servicesin-most-countries-who-survey. Accessed in May 27, 2021.

17. Arksey H, O'Malley L. Scoping studies: towards a methodological framework, International Int J Soc Res Methodol. 2005;8(1):19-32. https://doi.org/10.1080/1364557032000119616

18. World Health Organization. Tracking SARS-CoV-2 variants. Available from: https://www.who.int/en/activities/tracking-SARS-CoV-2variants/. Accessed in Aug 17, 2021.

19. Colquhoun HL, Levac D, O'Brien KK, Straus S, Tricco AC, Perrier $L$, et al. Scoping reviews: time for clarity in definition, methods, and reporting. J Clin Epidemiol. 2014;67(12):1291-4. https://doi. org/10.1016/j.jclinepi.2014.03.013

20. Peters MDJ, Godfrey C, Mclnerney P,MunnZ, Tricco AC, Khalil H. In: Aromataris E, Munn Z, editors. JBI Manual for Evidence Synthesis. Chapter 11: Scoping Reviews (2020 version). 2020. https://doi.org/10.46658/JBIMES-20-12

21. Tricco AC, Lillie E, Zarin W, O'Brien KK, Colquhoun H, Levac D, et al. PRISMA extension for scoping reviews (PRISMA-SCR): checklist and explanation. Ann Intern Med. 2018;169(7):467-73. https://doi. org/10.7326/M18-0850

22. Aromataris E, Munn Z, editors. JBI Manual for Evidence Synthesis Available from: https://synthesismanual.jbi.global. Accessed in Jun 3, 2021. 